\title{
Avaliação dos mecanismos de aderência entre argamassa colante e substrato não poroso
}

\author{
Evaluation of adherence mechanisms between adhesive \\ mortars and non-porous surface
}

\begin{abstract}
Eduardo Pereira
Isac José da Silva

Marienne do Rocio de Mello Maron da Costa

Resumo

Eduardo Pereira Departamento de Engenharia Civil Universidade Estadual de Ponta Grossa Av. Carlos Cavalcanti, 4748, Uvaranas

Ponta Grossa - PR - Brasil CEP $84030-900$

Tel.: (42) 3220-3077

engenheiroeduardopereira@gmail.com

Isac José da Silva Produtos Complementares, Departamento de Inovação \& Desenvolvimento, Setor de Pesquisa \& Desenvolvimento Votorantim Cimentos S/A Rodovia dos Minérios, 1303, Abranches

Curitiba - PR - Brasil CEP 82130-570

Tel.: (41) 3355-1176

E-mail: isac.silva@vcimentos.com.br

Marienne do Rocio de Mello Maron da Costa Departamento de Construção Civil, Setor de Tecnologia Universidade Federal do Paraná Centro Politécnico, Jardim das Américas, Sala 05.04 Curitiba - PR - Brasil CEP 80000-000

Tel.: (41) 3361-3010

E-mail: mariennecosta@uol.com.br

Recebido em 29/06/12

Aceito em 23/04/13

resistência de aderência de um sistema de revestimento cerâmico é uma das mais importantes propriedades deste tipo de acabamento. $\mathrm{O}$ conhecimento das propriedades dos substratos e argamassas, e a capacidade de bem avaliar a interação entre os elementos são preceitos básicos para construírem-se revestimentos duráveis. Nesse sentido, o

aperfeiçoamento dos modelos que descrevem os mecanismos de aderência, objetos de estudo deste trabalho, são essenciais, principalmente devido a diferenças nas características dos materiais relativas à porosidade, verificadas tanto em substratos como nas placas. O planejamento experimental consistiu no assentamento de um revestimento cerâmico externo utilizando-se a técnica de piso sobre piso, ensaios de resistência de aderência, aquisição de imagens em MEV dos pisos retirados do campo de testes e caracterização das argamassas colantes de estudo. Os resultados mostraram uma relação entre a resistência de aderência e a extensão de contato entre a argamassa e o substrato, indicando que o mecanismo de aderência para o assentamento de placas sobre substratos não porosos está diretamente relacionado com a extensão do contato entre os materiais, resultando em um modelo de aderência para o caso de revestimento cerâmico em substrato pouco poroso.

Palavras-chave: Aderência. Argamassa colante. Substratos não porosos.

\section{Abstract}

Adhesive strength of ceramic tile systems is one of the most import properties in this type of lining. The understanding of the properties of substrates and mortars, and especially the ability to evaluate the interaction between the elements are basic precepts for making durable finishings. Hence, improving the models that describe the mechanisms of adhesion, which is the focus of this paper, is important, particularly because of the differences in the porosity characteristics of the materials observed both in the substrate and in the tiles. The experiment consisted in the external application of ceramic coatings using the tile on tile technique, the adhesion strength test, SEM imaging of coating removed from the testing field, and the characterization of the adhesive mortars under study. The results showed a relationship between adhesive strength and length of contact between mortar and substrate, which indicates that the mechanism of adhesion for tiles applied on non-porous substrates is directly related to the extension of contact between the materials. Based on those results, a model of adhesion for ceramic coatings applied on non-porous substrate can be established.

Keywords: Adhesion. Adhesive mortar. Non-porous substrates.
\end{abstract}




\section{Introdução}

A utilização de revestimentos cerâmicos, seja em fachadas ou pisos, é uma solução construtiva e arquitetônica amplamente utilizada. Porém, apesar do desenvolvimento da indústria de produtos cerâmicos e dos procedimentos de colagem das peças, os problemas relacionados com o desplacamento de revestimento são ainda hoje uma manifestação patológica grave e frequente, registrada tanto nos primeiros anos de utilização quanto após longos períodos (SÁ, 2005; WETZEL; ZURBRIGGEN; HERWEGH, 2010). Segundo Silva (2003), o descolamento de placas cerâmicas é, sem dúvida, a manifestação patológica mais importante em revestimentos cerâmicos, preocupando mais pela segurança dos usuários do que pelo aspecto estético comprometido. Descolamentos são presenciados nas mais diversas situações de uso, principalmente em situações onde esses materiais ficam sujeitos às intempéries ou locais com umidade excessiva.

Nos últimos anos, segundo Wetzel, Zurbriggen e Herwegh (2010), tem aumentado a quantidade de manifestações patológicas de descolamento de placas cerâmicas, podendo esse aumento ser consequência dos diferentes materiais e técnicas empregados recentemente. Bauer e Castro (2010) verificaram que o descolamento e posterior desplacamento de cerâmicas representam a manifestação com maior incidência na cidade de Brasília. Ao analisar prédios de até 10 anos, os pesquisadores verificaram que aproximadamente $80 \%$ das manifestações eram de descolamento ou desplacamento. Em um estudo realizado em Porto Alegre, citado por Moura (2007), verificou-se que $67 \%$ das manifestações patológicas na cidade eram de fissuras e desplacamentos de cerâmicas.

Aderência é a ligação de natureza atômica ou molecular existente na interface entre um corpo sólido e outro qualquer, podendo ser essa ligação tanto física, obtida pelo engaste entre o substrato e o adesivo, quanto química, por meio de forças eletrostáticas de Van Der Walls (THURLER; FERREIRA, 1995). A NBR 13528 (ABNT, 2010) define aderência como a propriedade do revestimento de resistir às tensões normais e tangenciais atuantes na interface com o substrato. A norma cita ainda que a aderência não é uma propriedade exclusiva da argamassa, mas da interação entre as camadas do sistema, sendo necessário especificar o substrato em que a argamassa será assentada.

Segundo Carasek (1996), a aderência entre um substrato poroso e a argamassa ocorre através de um fenômeno essencialmente mecânico. Esse fenômeno é caracterizado pela transferência de água que ocorre entre a argamassa e o substrato, possibilitando a entrada da pasta de cimento nos poros do substrato, que, ao hidratar-se, precipita hidróxidos e silicatos que promovem a ancoragem do revestimento. A autora identificou através de microscopia a morfologia e a natureza dos produtos formados nessa região, e afirmou ser o intertravamento de cristais de etringita nos poros do substrato o principal responsável pela resistência de aderência. Nesse sentido, entende-se que a porosidade terá grande influência na aderência de revestimentos ao substrato.

Substratos com alta porosidade podem absorver grande quantidade de água e provocar uma hidratação inadequada do cimento da argamassa, ou seja, a quantidade de água restante na argamassa não seria suficiente para hidratar todo o cimento, formando regiões frágeis, com potencial de apresentar descolamento (BREA, 2003). Em situações contrárias, em um substrato pouco poroso, a baixa absorção não permite a entrada da pasta que promove a ancoragem, prejudicando a aderência entre os materiais.

Em substratos pouco porosos, durante a aplicação da placa cerâmica sobre a argamassa colante, é observado acúmulo de água na interface. Esse fenômeno pode ser comparado com o efeito parede encontrado na interface entre agregados e pasta de cimento. Assim, além de a baixa absorção de água do substrato restringir o mecanismo de aderência, pode também colaborar com o aparecimento do efeito parede. O acúmulo de água na interface placa/argamassa colante resulta numa região com alta relação a/c e, portanto, com alta porosidade e menor resistência mecânica (ALMEIDA, 2005).

A fim de minimizar o efeito gerado por substratos pouco porosos, a solução, segundo Nogami (2007), é alterar a superfície de contato, favorecendo a ancoragem através da rugosidade dos substratos, pois para revestimentos com pouca ou nenhuma absorção de água, a resistência de aderência está intimamente relacionada com a área de contato entre os materiais aderidos. Segundo Mansur (2007), uma solução para minimizar o efeito do acúmulo de água gerado pela baixa absorção do substrato é o uso de aditivos poliméricos. Esses, após secagem, formam um filme polimérico na interface argamassa/cerâmica, o qual aumenta a aderência do revestimento. Outra possibilidade de incremento na resistência de aderência está diretamente relacionada com alterações na trabalhabilidade das argamassas, na energia de impacto (processo de execução), nas características dos substratos e no controle de fatores externos (CARASEK, 2007). 
Além da aderência pelo fenômeno de ancoragem dos produtos de hidratação nos poros do substrato, Santos (2008) cita a influência de fenômenos químicos. Estes ocorrem em função da proximidade das moléculas do substrato e da argamassa colante, que se atraem pelas forças elétricas de Van Der Waals. As ligações de Van Der Walls são conduzidas por forças intermoleculares, entre moléculas eletricamente neutras, sendo estas responsáveis por muitos fenômenos físicos e químicos, como a adesão, o atrito e a viscosidade (GRILLO, 2010).

$\mathrm{O}$ entendimento do mecanismo de aderência entre os materiais que constituem o sistema de revestimento cerâmico de piso sobre piso e os fatores intervenientes nesta ligação são importantes, pois grande parte das manifestações patológicas observadas é devida a falhas nessa aderência. A técnica de assentamento de piso sobre piso é ainda recente, e o conhecimento sobre as propriedades do conjunto assentado necessita investigações mais detalhadas (PEREIRA et al., 2012). As informações disponíveis na literatura referem-se aos sistemas de revestimento cerâmico, formado por substrato poroso/argamassa colante/revestimento, não levando em consideração a interação da argamassa sobre um substrato não poroso, como é o caso de superfícies esmaltadas (assentamento sobre pisos cerâmicos antigos).

Embora as argamassas colantes industrializadas tenham sua comercialização consolidada e em plena expansão, a pesquisa sobre suas propriedades ainda merece atenção especial. A durabilidade e a consequente viabilidade do revestimento cerâmico como solução na construção civil dependem da fixação das peças cerâmicas ao substrato, o que tornam a discussão e o estudo do tema imprescindíveis.

Pereira, Carasek e Francinete Junior (2005) afirmam que o conhecimento das propriedades dos substratos e argamassas, e principalmente a capacidade de bem avaliar a interação entre a argamassa colante e o substrato são preceitos básicos para construírem-se revestimentos eficientes e duráveis. Nesse sentido, o aperfeiçoamento dos modelos que descrevem os mecanismos de aderência entre as argamassas/placas cerâmicas/substrato são essenciais, principalmente devido a diferenças nas características dos materiais quanto à porosidade, verificadas tanto em substratos (substratos de concreto, por exemplo) como em placas (pedras ornamentais, porcelanatos).

Com base no exposto, este trabalho avalia os mecanismos de aderência entre argamassa colante e um substrato não poroso, utilizando-se a técnica de assentamento de piso sobre piso. Resultados de ensaios de resistência de aderência e imagens em microscopia (MEV) são correlacionados e, ao final das discussões, um modelo para esse tipo de aplicação é apresentado.

\section{Materiais e métodos}

Para alcançar os objetivos propostos, desenvolveuse um projeto experimental que consistiu no assentamento de um revestimento cerâmico externo utilizando-se a técnica de piso sobre piso, com caracterização das argamassas colantes estudadas, ensaios de resistência de aderência e aquisição de imagens em MEV dos pisos retirados do campo de testes. Este trabalho é parte dos resultados obtidos a partir de um projeto de pesquisa desenvolvido entre a Universidade Federal do Paraná e a Votorantim Cimentos, que visa avaliar a eficiência das argamassas colantes de mercado para a aplicação da técnica de colagem de piso sobre piso.

Um sistema de revestimento cerâmico usual é o resultado do assentamento de uma placa cerâmica sobre uma base ou substrato, com a utilização de argamassa colante, formando um conjunto de camadas aderido e contínuo. A técnica de aplicação de piso sobre piso consiste no assentamento de uma nova camada cerâmica, utilizando-se argamassa colante em sobreposição a um sistema de revestimento cerâmico já existente. Nesse tipo de técnica, a superfície esmaltada da placa cerâmica antiga passa a ser o substrato do sistema e trata-se de um substrato não poroso. A Figura 1 apresenta um esquema da disposição de um sistema de revestimento do tipo piso sobre piso.

O planejamento experimental, a descrição dos materiais e métodos, e a forma de análise dos resultados são apresentados a seguir.

\section{Variáveis de estudo}

A principal variável neste trabalho é a argamassa colante utilizada, sendo selecionadas quatro argamassas colantes industrializadas, todas do tipo ACIII (revestimento externo), sendo cada uma de um fabricante diferente. O número de amostras analisadas foi definido de acordo com a área disponível para o assentamento externo dos pisos. As argamassas colantes foram escolhidas em função de sua disponibilidade nas lojas de materiais de construção na região de Curitiba, PR, buscando-se o uso das principais marcas do mercado local. 


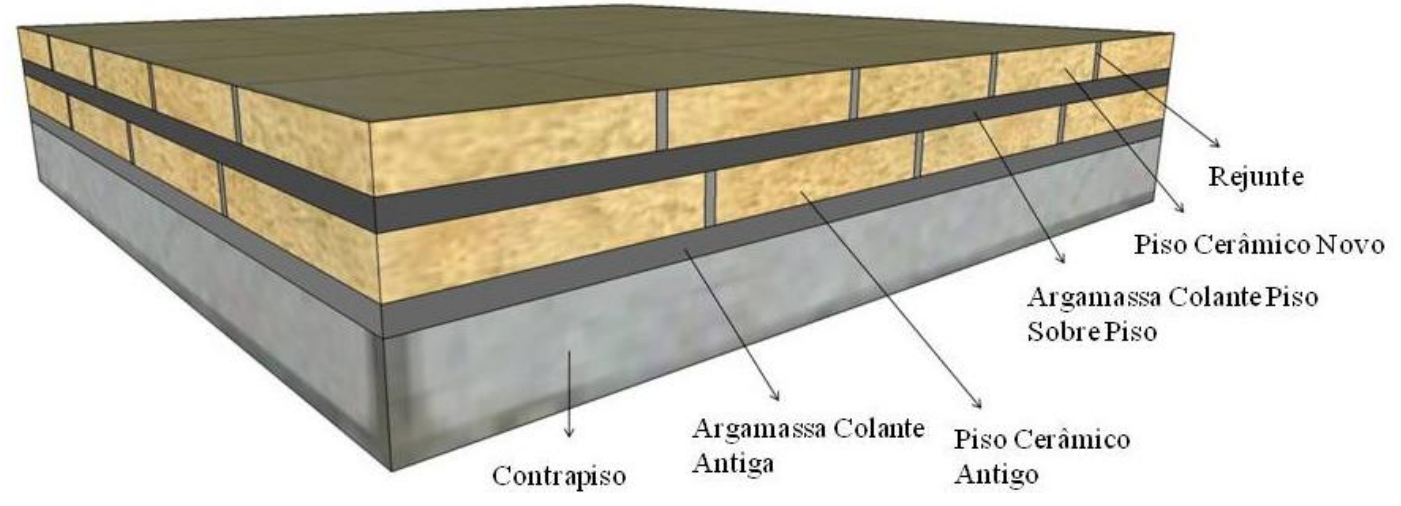

Figura 1 - Sistema de revestimento cerâmico assentado de piso sobre piso

\section{Caracterização das argamassas colantes}

Uma vez que as argamassas colantes aplicadas no estudo são industrializadas, foi necessário fazer uma reconstituição aproximada de sua composição, a fim de embasar as análises a respeito do comportamento dos sistemas de revestimento. Os ensaios utilizados foram resíduo insolúvel, termogravimetria, difração de raios $\mathrm{X}$ e granulometria a laser. Os procedimentos de caracterização de traços de argamassa tiveram como base Quarcioni (1998) e Costa (2006). A Tabela 1 apresenta um resumo das principais informações referentes à composição das argamassas colantes.

Procedeu-se também sobre as argamassas ao ensaio de fluorescência de raios $X$ para determinação da composição química das argamassas. Para execução da fluorescência de raios $X$, utilizou-se um equipamento da Philips modelo Magix Pro. A Tabela 2 apresenta os resultados de análises semiquantitativas por fluorescência de raios $\mathrm{X}$ para as argamassas colantes.

Os principais picos identificados pelos difratogramas no ensaio de DRX foram de quartzo, indicando a presença majoritária de areia quartzosa nas argamassas colantes.

\section{Assentamento externo do piso cerâmico e ensaio de resistência de aderência}

Para verificar o comportamento do sistema de revestimento em uma condição real, selecionou-se uma área de testes para assentamento de placas cerâmicas (Figura 2). A área situada na cidade de Curitiba, PR, tem aproximadamente $20 \mathrm{~m}^{2}$. Podese observar pela imagem do local que o piso possui muretas em todas as suas extremidades, o que representa uma restrição à movimentação livre dos revestimentos, simulando-se assim a condição comum de obras.
Nesta etapa do trabalho buscaram-se, em obras de reforma, pisos antigos que pudessem ser retirados sem danos para ser reassentados na área de teste, buscando-se simular, no estudo, uma área de piso usado. Obteve-se um lote suficiente para cobrir a área com um mesmo tipo de placa cerâmica, sendo estas com textura levemente aspera. Essas placas, tendo sido retiradas de uma construção já em uso, estiveram submetidas a diversas condições de exposições durante sua utilização na edificação, não sendo, no entanto, objetivo deste trabalho analisar o histórico delas. Deve-se ressaltar, no entanto, que, sendo utilizado o mesmo piso antigo para todas as argamassas, houve uma padronização da base, reduzindo-se assim a influência dessa variável sobre as análises.

Buscando-se uma condição ambiental mais favorável, a moldagem das argamassas ocorreu após um período de estiagem para que a chuva não interferisse de maneira significativa no desempenho dos revestimentos. É possível visualizar pela

Figura 3 que anteriormente aos ensaios de resistência de aderência aos 28 dias também houve um período com ausência de chuvas de aproximadamente 3 dias. A

Figura 3 apresenta também as temperaturas máximas e mínimas na cidade de Curitiba no período de testes.

Para a moldagem dos pisos, as argamassas colantes foram misturadas mantendo-se os cuidados como homogeneização e tempo de maturação. Para a mistura, uma vez que o volume de argamassa era necessariamente grande, utilizouse um balde de metal e um misturador mecânico. As relações água/argamassa e o tempo de maturação foram adotados conforme recomendação do fabricante (Tabela 3). O rejunte utilizado foi de marca encontrada no mercado. 
Tabela 1 - Resumo das principais características da composição das argamassas colantes, obtidas por reconstituição de traços

\begin{tabular}{c|c|c|c|c|c}
\hline $\begin{array}{c}\text { Argamassa } \\
\text { colante }\end{array}$ & Tipo de cimento $^{\mathbf{1}}$ & $\begin{array}{c}\text { Agregado total } \\
\mathbf{( \% )}\end{array}$ & $\begin{array}{c}\text { Aglomerante } \\
\mathbf{( \% )}\end{array}$ & $\begin{array}{c}\text { Aditivos } \\
(\boldsymbol{\%})\end{array}$ & $\begin{array}{c}\text { Material passante na } \\
\text { peneira 170 }^{\mathbf{( \% )}}\end{array}$ \\
\hline A & CPII F & 53,8 & 45,1 & 1,2 & 36,28 \\
B & CPII Z & 52,9 & 46,3 & 0,8 & 41,64 \\
C & CPII E & 48,9 & 48,9 & 1,4 & 25,94 \\
D & CPII Z & 67,7 & 31,7 & 0,5 & 23,17 \\
\hline
\end{tabular}

Nota: ${ }^{1}$ Conforme informações do fabricante; e

2Peneira de abertura $0,090 \mathrm{~mm}$.

Tabela 2 - Resultado do ensaio de fluorescência de raios X das argamassas colantes

\begin{tabular}{cccccccccccccc}
\hline Origem & $\begin{array}{c}\text { Perda } \\
\text { ao fogo }\end{array}$ & $\mathbf{S i O}_{\mathbf{2}}$ & $\mathrm{Al}_{\mathbf{2}} \mathbf{O}_{\mathbf{3}}$ & $\mathbf{F e}_{\mathbf{2}} \mathbf{O}_{\mathbf{3}}$ & $\mathbf{C a O}$ & $\mathbf{M g O}$ & $\mathbf{N a}_{\mathbf{2}} \mathbf{O}$ & $\mathbf{K}_{\mathbf{2}} \mathbf{O}$ & $\mathbf{P}_{\mathbf{2}} \mathbf{O}_{\mathbf{5}}$ & $\mathbf{S O}_{\mathbf{3}}$ & $\mathbf{T i O}_{\mathbf{2}}$ & $\mathbf{M N}_{\mathbf{2}} \mathbf{O}_{\mathbf{3}}$ & $\mathbf{S o m a}$ \\
\hline $\mathrm{A}$ & 6,35 & 64,036 & 2,386 & 0,624 & 20,001 & 4,031 & 0,181 & 0,528 & 0,093 & 1,566 & 0,118 & 0.000 & 100 \\
$\mathrm{~B}$ & 5,25 & 63,702 & 2,692 & 0,865 & 22,26 & 2,342 & 0,159 & 0,507 & 0,146 & 1,868 & 0,102 & 0,008 & 100 \\
$\mathrm{C}$ & 4,56 & 69,641 & 2,008 & 0,855 & 18,029 & 2,771 & 0,092 & 0,353 & 0,072 & 1,471 & 0,09 & 0,008 & 100 \\
$\mathrm{D}$ & 2,62 & 73,842 & 1,41 & 1,458 & 15,636 & 3,149 & 0.000 & 0.000 & 0,42 & 1,103 & 0,169 & 0,008 & 100 \\
\hline
\end{tabular}

Nota: resultados em porcentagem (\%).

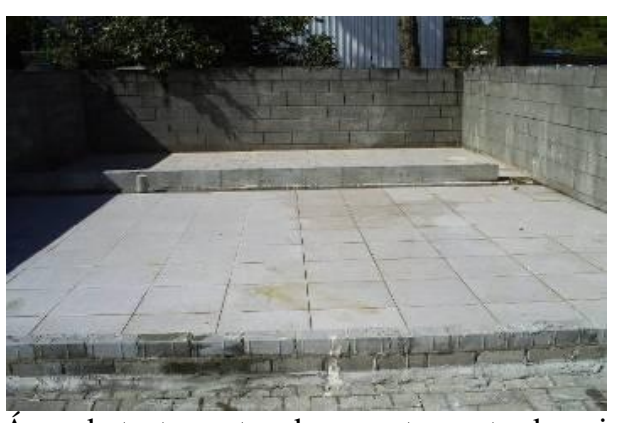

(a) Área de testes antes do assentamento dos pisos

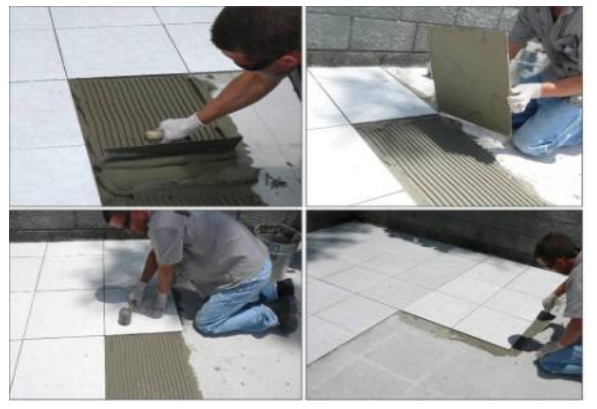

(b) Etapa do assentamento de piso sobre piso

Figura 2 - Área de teste para o assentamento das placas cerâmicas

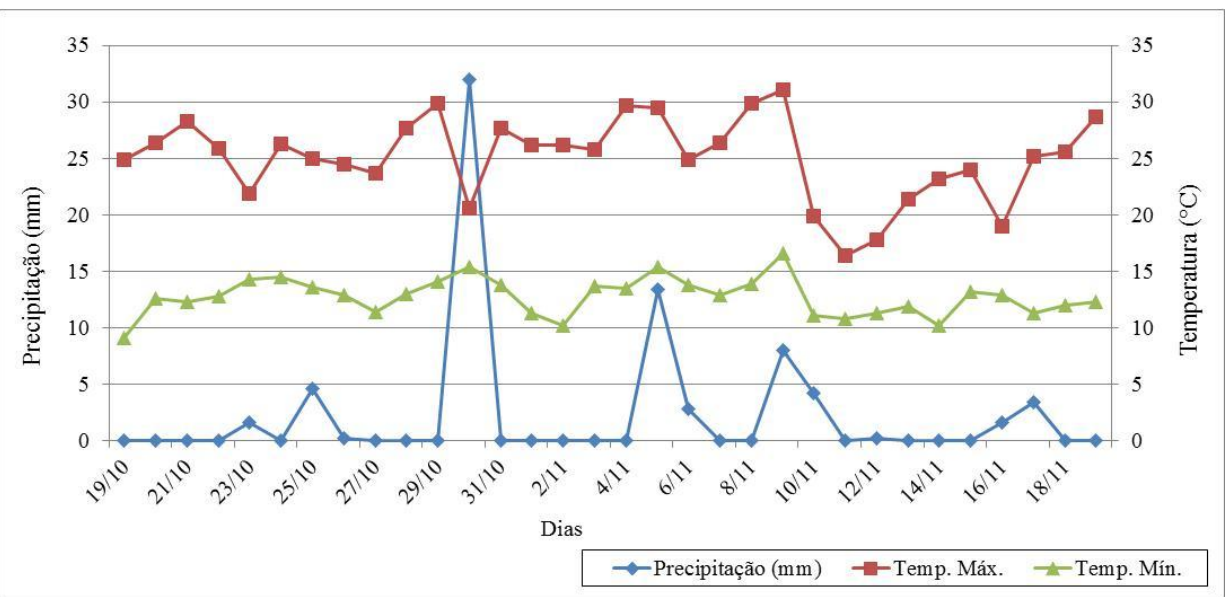

Figura 3 - Dados de precipitação de chuva, temperaturas máximas e mínimas diárias na cidade de Curitiba no período de ensaios de resistência de aderência

Fonte: Dados fornecidos pelo Instituto Tecnológico Simepar.

Tabela 3 - Resumo das principais características da moldagem das argamassas colantes

\begin{tabular}{ccc}
\hline Argamassa colante & Relação água/argamassa (\%) & Tempo de maturação (min) \\
\hline A & 21,0 & 0,0 \\
B & 29,0 & 15,0 \\
C & 23,0 & 15,0 \\
D & 21,5 & 10,0 \\
\hline
\end{tabular}


Após 28 dias do assentamento do piso sobre piso, executaram-se os primeiros ensaios de arrancamento, sendo ensaiados 10 pontos para cada argamassa. Utilizou-se uma serra de corte com disco diamantado para cortar as placas cerâmicas nas dimensões das pastilhas metálicas de arrancamento $(50 \times 50 \mathrm{~mm})$ até a profundidade do contrapiso. Após essa etapa, procedeu-se à colagem das pastilhas metálicas sobre as placas cerâmicas com um adesivo bicomponente à base de resina epóxi da marca Araldite. Após a cura da resina, realizaram-se os ensaios de resistência de aderência, seguindo procedimentos da NBR 13528 (ABNT, 2010) e NBR 14084 (ABNT, 2004). O equipamento utilizado para a execução dos ensaios de arrancamento é um modelo Dyna Z6, da marca Proceq, com manômetro digital integrado.

Conforme recomendação na NBR 14084 (ABNT, 2004), o tipo de ruptura foi registrado, bem como o percentual de argamassa que ficou retido no substrato, para o caso de ruptura na interface argamassa colante/substrato. Esse parâmetro permitiu inferir sobre o percentual de extensão de aderência entre a argamassa e o substrato.

Após os ensaios de arrancamento, procedeu-se ao tratamento dos dados adotando as recomendações da NBR 14084 (ABNT, 2004). Considerou-se válido o resultado encontrado quando, após eliminar os valores espúrios, pelo menos cinco valores se encontravam nos limites estipulados. A resistência de aderência é a média dos valores válidos após o tratamento inicial. Além da eliminação dos espúrios, procedeu-se sobre os dados a uma análise de variância (ANOVA).

\section{Análise de imagens por microscopia eletrônica de varredura (MEV)}

O MEV é um dos mais versáteis instrumentos disponíveis para a observação e análise de características microestruturais de objetos sólidos. A principal razão de sua utilização é a alta resolução que pode ser obtida quando as amostras são observadas; valores da ordem de 2 a 5 nanômetros são geralmente utilizados (NAGATANI et al., 1987). Outra característica importante é a aparência tridimensional da imagem das amostras, resultado direto da grande profundidade de campo.

Foram retiradas, utilizando-se serra de corte do tipo maquita, amostras do campo de teste com aproximadamente $7,0 \mathrm{~cm}^{2}$, com profundidade que alcançasse o contrapiso. Selecionaram-se 4 amostras por argamassa colante, retiradas de pontos aleatórios do revestimento externo, totalizando 12 amostras analisadas. Essas amostras foram levadas ao laboratório e, com o auxílio de uma serra de precisão, foram reduzidas até o tamanho suficiente para a análise no microscópio. O porta-amostra do equipamento tem seção circular de aproximadamente $2,5 \mathrm{~cm}$ de diâmetro e altura máxima da amostra de $1,5 \mathrm{~cm}$. O equipamento utilizado para o corte é conhecido como "cut-off", ou policorte, com discos abrasivos refrigerados (evitando deformações devido ao aquecimento) a relativas baixas rotações. As amostras, já no tamanho ideal para análise, foram embutidas a frio em resina, utilizando-se resina e catalisador da marca Arotec.

Após a cura da resina, as amostras foram lixadas manualmente, para eliminar imperfeições na superfície. A sequência de lixas adotadas foi: $\mathrm{n}^{\circ}$ 220, 320, 400, 600, 800, 1000 e 1200. Quanto mais baixo o número, mais grossa é a lixa, ou seja, maiores os grãos abrasivos. Após o lixamento, procedeu-se ao polimento das amostras visando a um acabamento superficial polido isento de marcas. Utilizou-se para esse fim pasta de alumina como abrasivo. O pano de polimento utilizado foi veludo.

As amostras polidas foram recobertas com ouro, buscando-se uma melhor condutibilidade das amostras, o que influencia diretamente na qualidade das imagens obtidas pelo MEV. Após a metalização, as amostras foram levadas ao microscópio eletrônico de varredura (MEV), Modelo FEI Phenom Tabletop Microscope.

\section{Resultados}

A Figura 4 apresenta os resultados de resistência de aderência aos 28 dias obtidos para as argamassas assentadas em ambiente externo. Os resultados foram tratados utilizando-se análise de variância (ANOVA), que demonstrou existirem diferenças significativas entre as argamassas, validando, assim, as análises.

Durante os ensaios de resistência de aderência verificou-se que a maioria das rupturas ocorreu na interface argamassa colante/superfície esmaltada da placa cerâmica antiga. Esse comportamento era esperado, uma vez que a superfície da placa cerâmica antiga é não porosa, característica que tende a tornar essa região a de ligação mais frágil devido à falta de ancoragem mecânica. $\mathrm{O}$ tipo de ruptura predominante foi argamassa colante/piso antigo. A Figura 5a apresenta os resultados médios de extensão de aderência obtidos por análise visual das superfícies de ruptura, e a Figura 5b, uma imagem da peça após o ensaio.

A Figura 6 apresenta imagens em MEV dessa interface para as argamassas estudadas. 


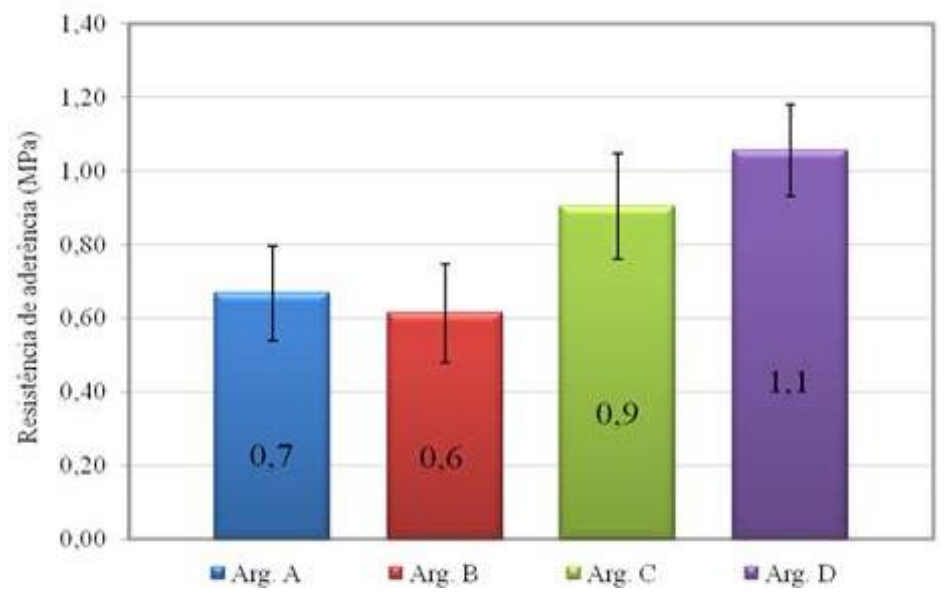

Figura 4 - Resistência de aderência dos revestimentos cerâmicos aos 28 dias

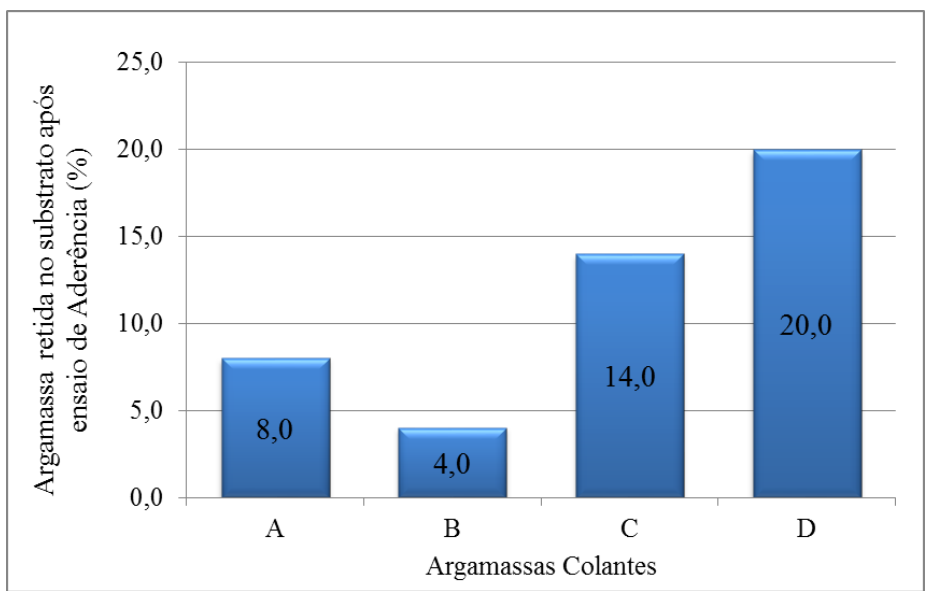

(a) Percentual médio de argamassa na superficie dos substratos após o ensaio de resistência de aderência, obtidos por análise visual da interface

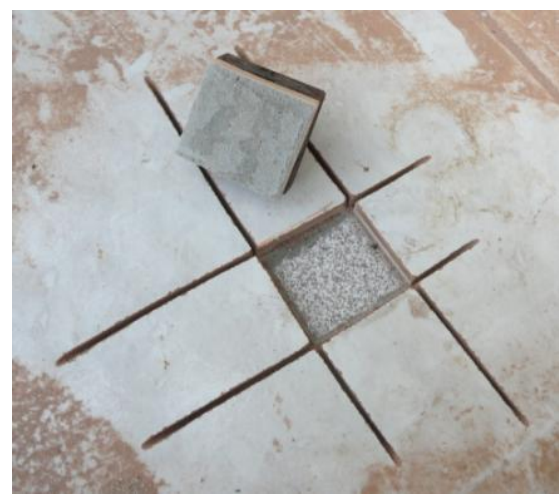

(b) Exemplo de revestimento após o ensaio de resistência de aderência

\section{Figura 5 - Tipos de rupturas}
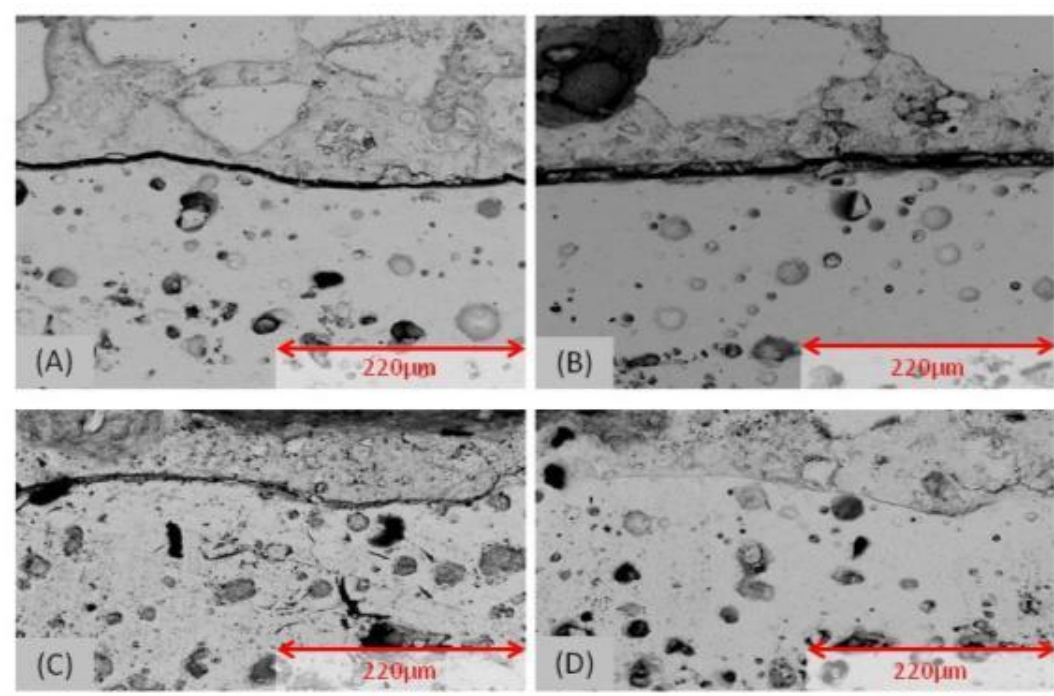

Figura 6 - Imagens em microscopia eletrônica de varredura (MEV) da interface entre os pisos antigos e argamassas colantes assentadas externamente, com aumento de 540 vezes 
Nas imagens é possível verificar uma forte correlação entre a extensão de contato das argamassas com a superfície e a resistência de aderência obtida nos ensaios em campo. A argamassa $\mathrm{D}$ é a que tem maior resistência de aderência (1,1 $\mathrm{MPa})$ e também é a que possui o melhor contato com a placa antiga. Por outro lado, a argamassa $\mathrm{B}$ é a que possui a menor aderência $(0,6 \mathrm{MPa})$ e a pior extensão de contato.

Outro fator que garantiu uma extensão de contato adequada para os revestimentos foi a área superficial das placas cerâmicas. Conforme relatado por Nogami (2007), a resistência de aderência em substratos pouco porosos está intimamente relacionada com a área de contato superficial entre os materiais aderidos. Sendo as placas cerâmicas antigas levemente asperas, elas tendem a apresentar área superficial consideravelmente maior do que uma placa cerâmica lisa. No caso específico deste trabalho, todas as placas eram iguais, independentemente da argamassa analisada, tendo seu efeito sobre as análises sido omitido. Recomenda-se que em outros trabalhos essa variável seja considerada.

A fim de investigar o comportamento de extensão de aderência do sistema, as amostras foram fraturadas para visualizar-se a superfície da argamassa colante que estava em contato com o piso antigo; posteriormente, estas foram analisadas em MEV. Na interface é possível observar a textura lisa da região de contato da argamassa com o piso antigo. Esse acabamento superficial é resultado do contato da argamassa com o esmalte do piso antigo, demonstrando um contato adequado entre eles. Observou-se também a presença de poros ou vazios distribuídos por toda a extensão da argamassa. Este pode ter sido resultado da tentativa de o ar aprisionado sair da mistura após sua moldagem. Para verificar os produtos formados nessa região, procedeu-se à aquisição de imagens dentro dos vazios observados. A Figura 7 mostra as fases hidratadas formadas nos poros das argamassas B e D.

É possível visualizar também a formação de uma grande quantidade de compostos hidratados nos poros próximos à interface da argamassa com o piso antigo. Pela forma dos compostos, é possível inferir sobre a presença de etringita, placas de hidróxido de cálcio (portlandita) e silicato de cálcio hidratado (C-S-H). A variação da morfologia e concentração de cada um nos poros da base e na região da interface irá influenciar a aderência. Ressalta-se que as conclusões obtidas e discutidas neste ponto não podem ser adotadas como conclusivas, uma vez que a quantidade de pontos analisada por microscopia é insuficiente para generalizar-se como um comportamento padrão para as argamassas colantes e a interface com o piso antigo. No entanto, os resultados permitem fazer algumas suposições sobre os mecanismos de aderência na região de interface piso antigo/argamassa colante.
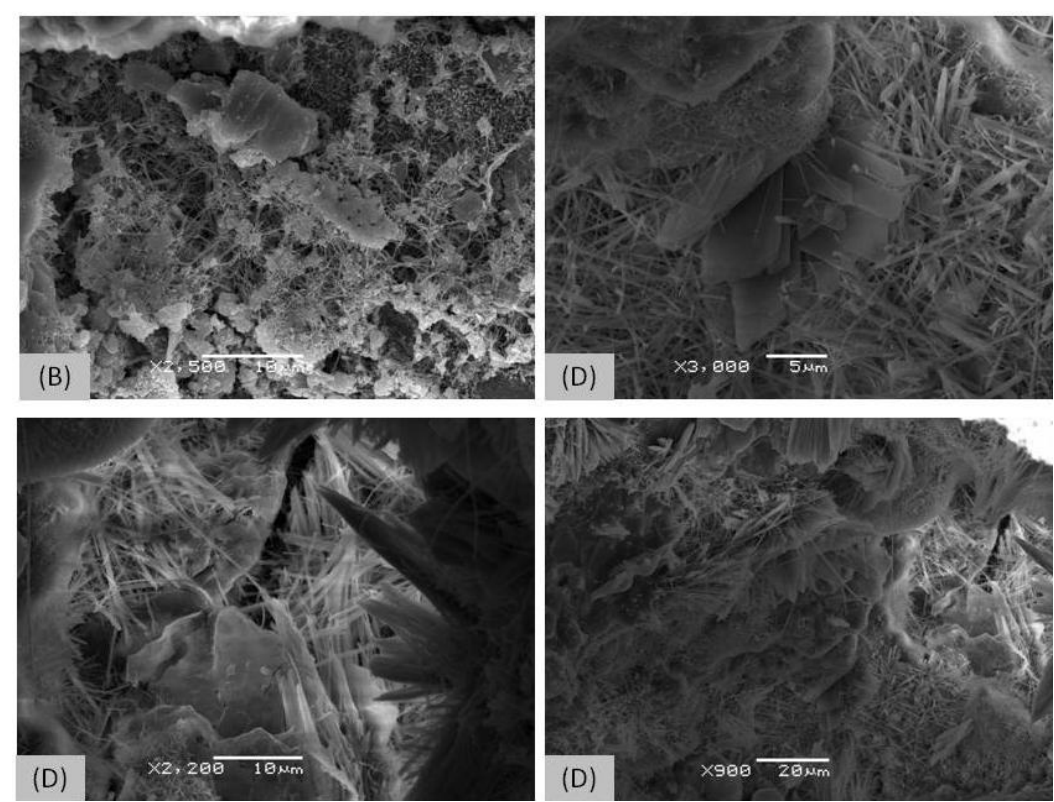

Figura 7 - Fases hidratadas formadas nos poros das argamassas na região da interface com o piso antigo 
Com base na aparência lisa da superfície da argamassa, o que indica que não houve penetração de compostos na placa, e na presença dos diversos compostos existentes na região de interface com as argamassas, é possível concluir que a resistência de aderência entre as camadas do sistema de revestimento de piso sobre piso seja proporcionada muito mais pela extensão de aderência entre a argamassa colante e o piso cerâmico do que pelo intertravamento dos compostos hidratados do cimento à peça cerâmica. Sendo a peça cerâmica esmaltada e com porosidade aproximadamente nula, essa hipótese era esperada e foi confirmada através dos experimentos. A Figura 8 apresenta um modelo simplificado da hipótese discutida neste trabalho do mecanismo de aderência de revestimentos de piso sobre piso em comparação ao modelo proposto por Carasek (1996).

Ao contrário do relatado por Carasek (1996) em seu estudo utilizando substratos porosos, para a aplicação de piso sobre piso (substrato não poroso) não foi observada uma concentração grande de etringita nessa região. Isso já era esperado, pois, ao analisar os dados de fluorescência de raios $\mathrm{X}$ (Tabela 2), verifica-se a baixa quantidade de $\mathrm{Al}_{2} \mathrm{O}_{3}$ que compõe o $\mathrm{C}_{3} \mathrm{~A}$ do cimento, que, ao hidratar-se, forma a etringita. Devido à presença de silicato de cálcio hidratado (C-S-H) na região de interface e sendo este composto a principal fase que confere resistência aos compostos cimentícios e densificação (redução da porosidade) da área, pode-se supor que, para o assentamento de piso sobre piso, a resistência de aderência é governada principalmente pela presença do composto C-S-H.

O estudo apresentado refere-se a um tipo de aplicação específico e pode representar com melhor precisão o mecanismo de aderência entre as argamassas colantes e os substratos pouco

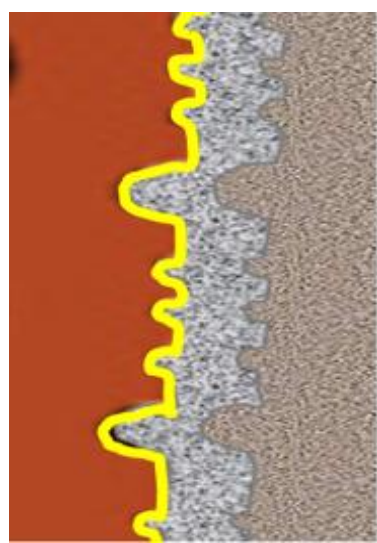

(a) Aderência por extensão de aderência porosos. O modelo proposto também apresenta outras questões envolvidas. Sendo o mecanismo de aderência governado pela extensão de contato, um cuidado especial deve ser tomado a fim de melhorar a ligação entre esses materiais. Tais cuidados podem ser desde a melhora da rugosidade das superfícies até a limpeza da base e formulação de argamassas com um comportamento reológico que proporcione um espalhamento da massa sobre a superfície, deixando menor volume de vazios com o menor esforço do assentador.

\section{Conclusões}

O mecanismo de aderência entre argamassa e substrato poroso é um assunto já discutido na literatura. Porém, o entendimento da aderência entre argamassa colante e substratos não porosos, como o caso do assentamento de piso sobre piso, merece um cuidado especial devido a certas diferenças em relação ao modelo tradicional (substratos porosos).

No substrato não poroso existe uma dificuldade ou impossibilidade de penetração de compostos cimentícios nos poros do substrato, o que gera a necessidade de avanço nesse campo de conhecimento. Os resultados desse experimento mostraram uma relação direta entre a resistência de aderência e a extensão de contato entre a argamassa e o substrato. Foi possível verificar que nesse tipo de substrato o contato físico na interface com a argamassa colante é governado pelas irregularidades do substrato e características reológicas da argamassa. Por outro lado, é mantido pelas características de adesividade da argamassa após contato físico possibilitado por suas características reológicas.

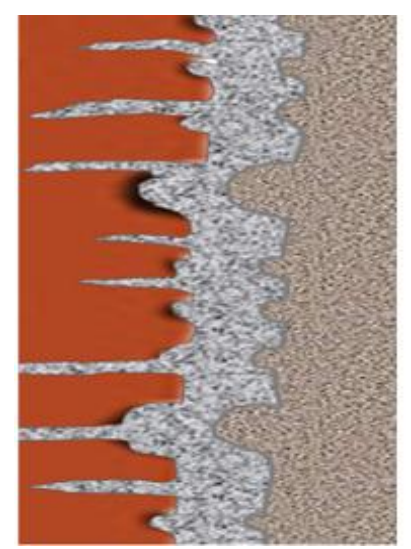

(b) Aderência por intertravamento da etringita nos poros

Figura 8 - Hipótese da resistência de aderência em revestimentos de piso sobre piso (a) em comparação ao modelo proposto por Carasek (1996) para revestimentos porosos (b) 
No modelo tradicional de aderência, a resistência de ligação é governada pela ancoragem dos produtos hidratados do cimento sobre os poros do substrato, principalmente a etringita. Neste trabalho, o que se verificou é que a quantidade de etringita formada na região de interface é pequena, fato confirmado pela FRX, o que permite afirmar não ser responsabilidade deste composto a aderência do conjunto. Por outro lado, pode-se atribuir a resistência de aderência à redução de porosidade da interface devido à presença do $\mathrm{C}-\mathrm{S}$ $\mathrm{H}$ e, consequentemente, à melhora do contato entre a placa e a argamassa. Dessa forma, o presente trabalho confirma um modelo de mecanismo de aderência para o caso de revestimento cerâmico em substrato pouco poroso.

\section{Referências}

ALMEIDA, A. E. F. S. Estudo da influência das Adições de Sílica Ativa e Copolímero Estireno Acrílico nas Propriedades de Argamassas Para o Assentamento de Porcelanato. São Carlos, 2005. Tese (Doutorado em Engenharia Civil) Área Interunidades em Ciência e Engenharia de Materiais da Universidade de São Paulo, São Carlos, 2005.

\section{ASSOCIAÇÃO BRASILEIRA DE NORMAS}

TÉCNICAS. NBR 13528: revestimento de paredes e tetos de argamassas inorgânicas: determinação da resistência de aderência à tração. Rio de Janeiro, 2010.

\section{ASSOCIAÇÃO BRASILEIRA DE NORMAS} TÉCNICAS. NBR 14084: argamassa colante industrializada para assentamento de placas cerâmicas: determinação da resistência de aderência à tração. Rio de Janeiro, 2004.

BAUER, E.; CASTRO, E. K. Patologias Mais Correntes nas Fachadas de Edifícios em Brasília. In?: CONGRESSO PORTUGUÊS DE ARGAMASSAS DE CONSTRUÇÃO, 3., Lisboa, 2010. Anais... Lisboa, 2010.

BREA, F. M. Resistência de Aderência e Tempo em Aberto de Argamassas Colantes Com Adição de Éteres de Celulose. In: SIMPÓSIO BRASILEIRO DE ARGAMASSAS, 5., São Paulo, 2003. Anais... São Paulo, 2003.

CARASEK, H. Aderência de Argamassas à Base de Cimento Portland a Substratos Porosos: avaliação dos fatores intervenientes e contribuição ao estudo do mecanismo da ligação. São Paulo, 1996. Tese (Doutorado em Engenharia Civil) Escola Politécnica, Universidade de São Paulo, São Paulo, 1996.
CARASEK, H. Argamassas. In: ISAIA, G. C. (Org.). Materiais de Construção Civil. São Paulo: Instituto Brasileiro do Concreto, 2007. v. 1.

COSTA, M. R. M. M. Análise Comparativa de Argamassas Colantes de Mercado Através de Parâmetros Reológicos. São Paulo, 2006. Tese (Doutorado em Engenharia Civil) - Escola Politécnica, Universidade de São Paulo, São Paulo, 2006.

GEMELLI, E. Corrosão de Materiais Metálicos e Sua Caracterização. Rio de Janeiro: LTC. 2001.

GRILLO, K. V. F. Análise Comparativa da Aderência de Tipos Rochosos Assentados Com Três Argamassas. São Carlos, 2010. Dissertação (Mestrado em Engenharia Civil) - Escola de Engenharia de São Carlos, Universidade de São Paulo, São Carlos, 2010.

MANSUR, A. A. P. Mecanismo Físico-Químico de Aderência na Interface Argamassa Modificada Com Polímeros/Cerâmica de Revestimento. Belo Horizonte, 2007. Tese (Doutorado em Engenharia Civil) - Escola de Engenharia, Universidade Federal de Minas Gerais, Belo Horizonte, 2007.

MOURA, C. B. Aderência de Revestimentos Externos de Argamassa em Substratos de Concreto: influências das condições de temperatura e ventilação na cura do chapisco. Porto Alegre, 2007. Dissertação (Mestrado) Escola de Engenharia, Universidade federal do Rio Grande do Sul, Porto Alegre, 2007.

NAGATANI, T. et al. Development of an Ultra High Resolution Scanning Electron Microscope by Means of a Field Emission Source and in-Lens System. Scanning Microscopy, v. 11, p. 901-909, 1987.

NOGAMI, L. Fixação de Placas de Rochas Ornamentais: estudo da aderência com argamassa colante. São Carlos, 2007. Dissertação (Mestrado em Geotecnia) - Escola de Engenharia de São Carlos, Universidade de São Paulo, São Carlos, 2007.

PEREIRA, P. C.; CARASEK, H.; FRANCINETE JUNIOR, P. Influência da Cura no Desempenho Revestimentos Com Argamassa Inorgânica. In: CONGRESSO PORTUGUÊS DE ARGAMASSAS E ETCS, 4., Coimbra, 2005. Anais... Coimbra, 2005. 
PEREIRA, E. et al. Análise Crítica da Aplicação do Ensaio de Resistência de Aderência Para Avaliar Argamassas Colantes Usadas no Assentamento de Piso Sobre Piso. In: SIMPÓSIO BRASILEIRO DE TECNOLOGIA DE ARGAMASSAS, 6., Florianópolis, 2012. Anais... Florianópolis, 2012.

QUARCIONI, V. A. Reconstituição de Traço de Argamassas: atualização do Método IPT. São Paulo, 1998. Dissertação (Mestrado em Engenharia Civil) - Escola Politécnica, Universidade de São Paulo, São Paulo, 1998.

SÁ, A. M. V. D. O. Durabilidade de Cimentos Cola em Revestimentos Cerâmicos Aderentes a Fachadas. Porto, 2005. Dissertação (Mestrado em Engenharia Civil) - Faculdade de Engenharia, Universidade do Porto, Porto, 2005.

SANTOS, H. B. Ensaio de Aderência das Argamassas de Revestimentos. Belo Horizonte, 2008. Monografia (Curso de Especialização em Construção Civil) - Escola de Engenharia, Universidade Federal de Minas Gerais, Belo Horizonte, 2008.
SILVA, C. O. Análise Crítica dos Requisitos e Critérios de Qualidade da Argamassa Colante. São Paulo, 2003. Dissertação (Mestrado em Engenharia Civil) - Escola Politécnica, Universidade de São Paulo, São Paulo, 2003.

THURLER, C. L.; FERREIRA, V. A. A Evolução da Resistência de Aderência de Algumas Argamassas Colantes Nacionais. In: SIMPÓSIO DE TECNOLOGIA DE ARGAMASSAS, 1., Goiânia, 1995. Anais... Goiânia, 1995.

WETZEL, A.; ZURBRIGGEN, R.; HERWEGH, M. Spatially Resolved Evolution of Adhesion Properties of Large Porcelain Tiles. Cement and Concrete Composites, v. 32, n. 5, p. 327-338, maio, 2010.

\section{Agradecimentos}

Os autores agradecem à Votorantim Cimentos pela parceria neste trabalho à colaboração dos laboratórios de Análise de Minerais e Rochas da UFPR e do Centro de Microscopia da UFPR.

Revista Ambiente Construído

Associação Nacional de Tecnologia do Ambiente Construído

Av. Osvaldo Aranha, $99-3^{\circ}$ andar, Centro

Porto Alegre - RS - Brasil CEP 90035-190

Telefone: +55 (51) 3308-4084

Fax: +55 (51) 3308-4054

www.seer.ufrgs.br/ambienteconstruido

E-mail: ambienteconstruido@ufrgs.br 